Article

\title{
Natural Brucella melitensis Infection and Rev. 1 Vaccination Induce Specific Brucella O-Polysaccharide Antibodies Involved in Complement Mediated Brucella Cell Killing
}

\author{
Shubham Mathur 1,2 (D), Menachem Banai ${ }^{2}$ and Dani Cohen ${ }^{1, *}$ \\ 1 Department of Epidemiology and Preventive Medicine, School of Public Health, Sackler Faculty of Medicine, \\ Tel Aviv University, Tel Aviv 6997801, Israel; shubhamm@mail.tau.ac.il \\ 2 Kimron Veterinary Institute, Beit Dagan 5025001, Israel; menachemba48@gmail.com \\ * Correspondence: dancohen@tauex.tau.ac.il; Tel.: +972-3-6407081
}

check for

updates

Citation: Mathur, S.; Banai, M.;

Cohen, D. Natural Brucella melitensis Infection and Rev. 1 Vaccination

Induce Specific Brucella

O-Polysaccharide Antibodies

Involved in Complement Mediated

Brucella Cell Killing. Vaccines 2022, 10,

317. https://doi.org/10.3390/

vaccines 10020317

Academic Editor: Tatsuya Yamazaki

Received: 23 December 2021

Accepted: 13 February 2022

Published: 17 February 2022

Publisher's Note: MDPI stays neutral with regard to jurisdictional claims in published maps and institutional affiliations.

Copyright: (c) 2022 by the authors. Licensee MDPI, Basel, Switzerland. This article is an open access article distributed under the terms and conditions of the Creative Commons Attribution (CC BY) license (https:// creativecommons.org/licenses/by/ $4.0 /)$.

\begin{abstract}
Vaccination against brucellosis using live attenuated strains is the primary approach in protecting livestock against the disease through a strong cellular immune response. Attenuated vaccine strains also induce serum anti-Brucella antibodies, mostly against Brucella O-polysaccharide, but their role in protection against the disease remains unclear. In this study, we show that Brucella OPS serum antibodies after vaccination or natural infection could kill Brucella in vitro as shown by the serum bactericidal activity (SBA) assay. We used serum samples of Rev. 1 vaccinated sheep that were negative or positive for Brucella OPS antibodies by either one of complement fixation test (CFT), microplate agglutination test (MAT) and ELISA, or sera of naturally infected sheep positive by CFT. We found a significant increase in the killing ability of sera 30 days after intraocular vaccination with Rev. 1 as compared with pre-vaccination. SBA was significantly higher in sera containing Brucella OPS IgG antibodies in comparison with sera lacking such antibodies ( $p<0.001$ against $16 \mathrm{M} \&$ Rev. 1 strains). All 10 sera of convalescent sheep demonstrated significant killing ability against the $16 \mathrm{M}$ B. melitensis field strain. Specific OPS antibodies participate in the in vitro complement mediated Brucella killing suggesting a potential role in protection against the disease through this mechanism and relevance of developing OPS-based Brucella vaccines.
\end{abstract}

Keywords: Brucella melitensis; serum; bactericidal activity; O-polysaccharide; Brucella OPS IgG antibodies

\section{Introduction}

Brucellosis severely affects animal and human health [1]. Brucella species belong in the Gram-negative group, partly classified according to their natural affiliation to distinct animal species. To date, 12 species have been validly published but only three, $B$. melitensis, B. abortus and B. suis associated with small ruminant, bovid and swine brucellosis, respectively, are the most distinct human pathogens. Moreover, small ruminants that are natural hosts of $B$. melitensis, establish a critical vehicle in transmitting the disease to humans, and partly to bovines. Brucella species cause abortion storms in their natural animal hosts followed by excessive shedding of the bacteria via contaminated placenta, fetus membranes and fluids, which leads to spreading of free Brucella organisms in the farm and environment [2]. Brucellosis is transmitted to humans through their contact with infected animals or with contaminated material such as aborted placenta or following consumption of contaminated raw milk and dairy products. In humans, brucellosis is frequently confused with flu-like symptoms but may exacerbate into complications such as endocarditis, meningitis and osteo-articular or epididymo-orchitis manifestations, and may rarely be lethal [3].

Controlling the disease in the livestock population is the most effective approach in preventing human cases and reducing the overall burden of disease in both the animal and human health systems. An ideal brucellosis control program consists of prophylactic vaccination of the livestock with live attenuated strains, smooth B. abortus S19 strain or rough 
B. abortus RB51 in cattle and B. melitensis Rev. 1 in small ruminants, respectively [4-6]. A test and cull policy after serological confirmation might complement successful eradication campaigns where possible, as owner compensation is mandatory in such cases [7]. Such a dual control policy has been implemented successfully in Israel throughout the years, resulting in minimizing the problem of $B$. melitensis $[8,9]$ but failure to sustain the program due to budgetary concerns has hampered these achievements.

The host first encounters Brucella by mediating an innate bactericidal response against organisms residing extracellularly with a successive development of an effective protective cellular response [10]. The live vaccine strains resembling their field strains in engaging the host immune system only after entrance establish a Th1 immune response involving humoral and cell-mediated B and T cells [11-13]. Importantly, these vaccines protect against abortion and therefore reduce bacterial spread in the farm, thereby decreasing the economic and health burden in the farm. However, despite achieving effective vaccination coverage with the live strains, Israeli dairy herds and many small ruminants have been consistently infected with $B$. melitensis field strains inferring on lack of protection against bacterial entrance to the host [9].

Here, we hypothesized that anti-Brucella OPS antibodies might fulfil the missing fragment in sustaining herd protection. Previous mice experiments have resulted with controversies regarding the specific contribution serum antibodies might play in host protection against Brucella challenges [11,14-18]. In light of the unresolved disagreement, we have revisited the question whether anti-Brucella OPS serum antibodies could be protective against brucellosis through complement mediated killing of Brucella cells during the extracellular stage of infection.

In this study we show that anti-Brucella OPS antibodies developed post-vaccination or following natural field infection kill Brucella in vitro as revealed by the serum bactericidal activity assay $[19,20]$. These findings open new horizons to developing a successful Brucella OPS-conjugate vaccine as recently suggested by Bundle and McGiven $[18,21,22]$ that could induce high levels of such functional antibodies.

\section{Material and Methods}

\subsection{Bacteria}

B. melitensis $16 \mathrm{M}$, a smooth virulent Brucella type strain (Received in the laboratory from INRA, (Institut National de la Recherche Agronomique (INRA) 75007 Paris, France), and B. melitensis vaccine strain Rev. 1 Elberg, passage 101, 1970, recommended by the WHO as an authentic vaccine strain for commercial production for sheep and goats (received directly from Dr. Elberg as a freeze-fried powder) were used in the study. The two strains are stored as glycerol frozen suspensions at the Israeli OIE and FAO Reference Laboratory for Brucellosis, Kimron Veterinary Institute, Israel. For an experimental use, these frozen suspensions were reconstituted on Tryptic Soy agar plates supplemented with SerumDextrose solution [23].

\subsection{Serum}

Sheep vaccination and monitoring against brucellosis is mandatory in Israel (Small ruminant health-Veterinary Services (in Hebrew), Last up-dating 15.03.2021 Available online: https:/ /www.gov.il/he/departments/general/sheep-health-veterinary-services (accessed on 9 February 2022). The Israeli Veterinary Services employ a single, lifelong dose of an ocular Rev. 1 vaccine, at 1-2 × 109 CFU/per animal. Vaccination is restricted to female ewe-lambs at ages 3-6 months. Males are not vaccinated but used as sentinel in monitoring herds for the disease. Animals which are intended for trade are checked serologically by Complement Fixation Test (CFT) and Microplate Agglutination Test (MAT). Otherwise, in case of suspected disease, all adult females are tested serologically by CFT.

Sheep serum samples from 2 different flocks at different time periods were taken by staff personnel of the Israeli Veterinary Services during routine surveillance and control activities and collected into Vacuette tube for serum separation. 
Serum samples from infected sheep were collected from animals in a bacteriologically confirmed infected flock. Ocular Rev. 1 vaccination of female ewe-lambs was conducted as part of the Israeli Veterinary Services vaccination program in one flock known to be brucellosis free, and sera samples were obtained from the animals before vaccination at day 0 , and after vaccination at day 15 and day 30. All serum samples were stored at $4{ }^{\circ} \mathrm{C}$ until their use. Anti-Brucella OPS serological titers were tested by complement fixation test (CFT, titer conversion to $\mathrm{IU}=\times 1.6)$ and microplate agglutination test $(\mathrm{MAT}$, titer conversion to $\mathrm{IU}=\times 1.905)[24]$.

\subsection{Indirect ELISA for Brucella-OPS Antibodies}

Besides conducting the standard serological tests, sera obtained in the vaccine experiment were evaluated for presence of anti-Brucella OPS antibodies by ELISA using the commercially available kit ID Screen ${ }^{\circledR}$ Brucellosis Serum Indirect Multi-Species (IDVET, Amman, Jordan). Results were expressed in OD values measured at $450 \mathrm{~nm}$ as indicated by manufacturer.

\subsection{Serum Bactericidal Activity}

Fresh bacterial cultures of B. melitensis $16 \mathrm{M}$ and B. melitensis Rev. 1 passage 101 Elberg strain were grown in Tryptic Soy broth (TSB), for 2 days at $37{ }^{\circ} \mathrm{C}$ in presence of $5 \% \mathrm{CO}_{2}$ atmosphere. Bacterial suspensions were centrifuged at $10,000 \times g$ for 10 min and cell pellets were suspended in PBS-containing $0.5 \mathrm{mM} \mathrm{MgCl}_{2}$ and $0.15 \mathrm{mM} \mathrm{CaCl}_{2}$, and cells were serially diluted to reach a cell concentration of $10^{4} \mathrm{CFU}$ per $\mathrm{ml}$. Each serum sample was tested in four separate experiments, in duplicates using Oswald et al. (1990) method with minor modifications [25]. Shortly, sheep serum was heat-inactivated at $56^{\circ} \mathrm{C}$ for $30 \mathrm{~min}$, and $50 \mu \mathrm{L}$ were mixed with $30 \mu \mathrm{L}$ of the master Brucella dilution in 96-well flat-bottomed polystyrene microtiter plates (Nunc ${ }^{\mathrm{TM}}$ Thermo scientific, Rochester, NY, USA). Cells were incubated in presence of $5 \% \mathrm{CO}_{2}$ atmosphere, keeping the plate rotated at $100 \mathrm{rpm}$ for $30 \mathrm{~min}$ at $37^{\circ} \mathrm{C}$, which allowed Brucella cells to interact with antibodies. After $30 \mathrm{~min}, 40 \mu \mathrm{L}$ of human complement (Quidal, San Diego, CA, USA) was added to the Brucella-serum reaction mixture and incubation at $37^{\circ} \mathrm{C}$ was continued for additional $1.5 \mathrm{~h}$. Then, a $25 \mu \mathrm{L}$ aliquot from each well (estimated number of 62 CFU in the untreated suspension) was plated in duplicates on Serum-Dextrose tryptic soy agar plates and incubated for 2 days at $37{ }^{\circ} \mathrm{C}$ with $5 \% \mathrm{CO}_{2}$ for $\mathrm{CFU}$ counting. Two control experiments were conducted, a Brucella cell suspension incubated in presence of buffer without serum and a Brucella cell suspension incubated in presence of complement but without serum, respectively. Because results showed only a minimal cell killing by the two systems, around 2-3\% (data not shown), we used the complement reaction mixture as our negative control in further calculations $[11,26]$. The percentage of cell killing (killing efficiency) was calculated as follows.

$$
\% K=100 x\left\{1-\left(\frac{\text { mean no.of CFU after incubation with serum and complement }}{\text { mean no. of CFU after incubation only with complement }}\right)\right\}
$$

\subsection{Statistical Analysis}

Graphpad Prism (Graphpad Prism. Available online: https:/ /www.graphstats.net/ graphpad-prism (accessed on 19 July 2021) was used for statistical analysis. Bonferroni's multiple comparison tests was used to analyze significance of differences of Brucella cell killing between serum samples of non-vaccinated and vaccinated ewes according to postvaccination time periods two ways ANOVA unweighted analysis was employed (Bonferroni post hoc test was used to analyze significance of differences between serum activity without or in presence of anti-Brucella OPS antibodies. Unpaired $t$-test was used to identify the Brucella killing by post-infection serum samples. 


\section{Results}

\subsection{Serology and Serum Bactericidal Activity}

3.1.1. Serology and Serum Bactericidal Activity (SBA) of Post-Vaccination Sera of Flock 1

B. melitensis Rev. 1 strain vaccination is used routinely in Israel in young replacement ewe-lambs as a full dose (1-2 × $\left.10^{9} \mathrm{cfu}\right)$ ocular application. This vaccination approach was introduced in the 1980s as a method of differentiating infected from vaccinated animals (DIVA) solution to minimize post-vaccine humoral antibody titers [7]. About $40 \%$ of the animals have been found negative in the MAT and CFT tests (unpublished data). We chose this platform to specifically test our hypothesis regarding development of complement mediated anti-Brucella OPS serum bactericidal activity (SBA) of antibodies induced by vaccination. We used B. melitensis strain $16 \mathrm{M}$, a type strain of the genus, and strain B. melitensis Rev. 1, Elberg passage 101, 1970, a reference vaccine type strain, as readout cells, addressing the potential attenuation of strain Rev. 1 in this pathway.

Three time periods were chosen, day 0 before vaccination, and 15 and 30 days postvaccination, respectively. Day 0 expressing SBA before animal vaccination, e.g., in naïve animals with background serum components in comparison to post-vaccination time periods that anticipate contribution of serum-developed anti-Brucella OPS antibodies to Brucella cell killing.

As shown in Table 1, our initial experiment included four animals which were tested before and after vaccination with Rev. 1 as mentioned above. None had detectable antibody titers by both MAT and CFT before vaccination. Serum number 9914 was negative for anti-Brucella OPS by CFT and MAT during the whole experiment. In contrast, serum number 9912 had positive MAT titers on day 30 but was CFT-negative along this period, and serum numbers 9913 and 9921 that showed MAT titers at early days after vaccination (day 15) became responsive also in the CFT test at day 30. Cell killing of both strains increased according to the post-vaccination time period but the extent of cell killing between individual serum samples and time periods varied. SBA of the consecutive sera of 3 of 4 animals was significantly higher on days 15 and 30 post vaccination against both Rev. 1 and 16M strains ( $p<0.0516 \mathrm{M} ; p<0.01$ Rev. 1, Bonferroni's multiple comparison test). Serum number 9914 that lacked anti-Brucella OPS antibodies along the whole experiment showed nevertheless a strong SBA activity even at time 0 that is before vaccination. As shown in Supplementary Material Figures S1 and S2, this result was unexpected, as other naïve serum samples only killed Brucella cells at background levels assumably associated with nonspecific cross-reactive antibodies. Accordingly, one might link the higher SBA activity of serum sample 9914 with presence of non-Brucella reactive serum components.

Table 1. Anti-Brucella-OPS serum titers depicted by MAT and CFT in the first vaccine experiment before and after ocular vaccination with $B$. melitensis Rev. 1 vaccine.

\begin{tabular}{|c|c|c|c|c|c|c|}
\hline \multirow{2}{*}{$\begin{array}{l}\text { Serum Identity } \\
\text { Number }\end{array}$} & \multicolumn{2}{|c|}{ Before Vaccination (Day 0) } & \multicolumn{2}{|c|}{15 Days Post Vaccination (Day 15) } & \multicolumn{2}{|c|}{30 Days Post Vaccination (Day 30) } \\
\hline & MAT & CFT & MAT & CFT & MAT & CFT \\
\hline 9912 & Neg & Neg & Neg & Neg & $1: 80(+3)$ & Neg \\
\hline 9913 & Neg & Neg & $1: 40(+3)$ & Neg & $1: 80(+3)$ & $1: 5(+3)$ \\
\hline 9914 & Neg & Neg & Neg & Neg & Neg & Neg \\
\hline 9921 & Neg & Neg & $1: 40(+3)$ & Neg & $1: 80(+3)$ & $1: 20(+3)$ \\
\hline
\end{tabular}

Neg stands for Negative.

Figure 1 summarizes the mean value of the collective SBA activities of the 4 sera samples against Rev. 1 and $16 \mathrm{M}$ strains at the 3 timings related to vaccination. Prevaccination naïve sera (day 0) had an SBA of around 10\% cell killing against both Brucella strains, $16 \mathrm{M}$ and Rev.1. As post-vaccination time period increased, there was increased killing activity by the serum samples against both strains ( $p \leq 0.0001$, two-way ANOVA). The mean SBA was highest on day 30 post-vaccination with percentages of cell killing 
significantly higher against $16 \mathrm{M}$ than against Rev. 1 ( $p<0.001$, Bonferroni post hoc test). As depicted in Table 1, at this time after vaccination, 3 out of 4 and 2 out of 4 sera, had elevated IgM and IgG antibody titers against Brucella OPS, respectively.

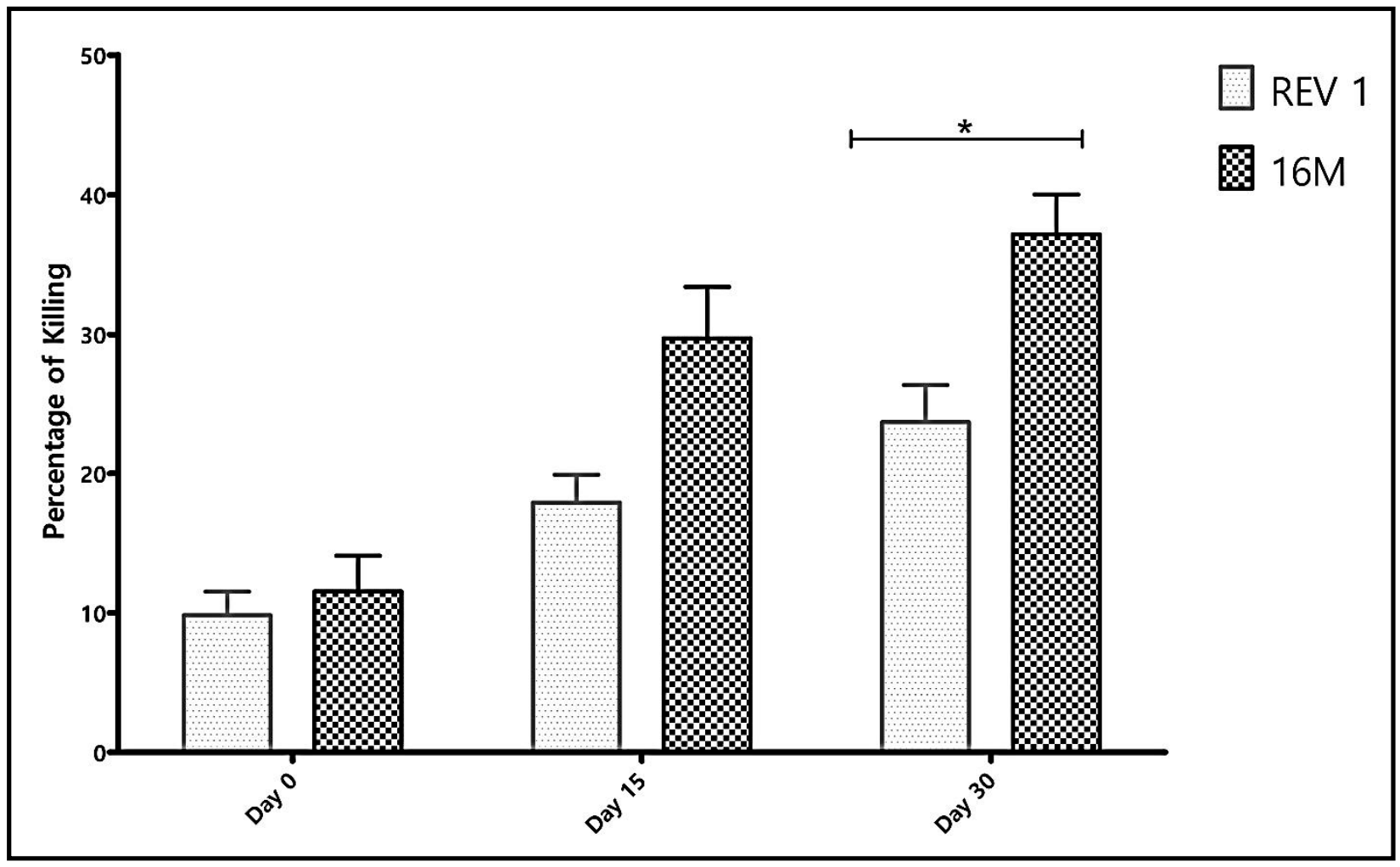

Figure 1. Arithmetic mean value of the combined percentages of Brucella cell killing of the four serum samples in correlation with post-vaccination time period. Percentage of cell killing is increased with post-vaccination time course (two-way ANOVA $p<0.001$ ). Bonferroni post hoc test analysis of the mean values showed stronger killing of $16 \mathrm{M}$ in comparison to Rev.1 among all serum samples tested, being non-significant at day $0(p>0.05)$; and day $15(p>0.05)$ and turning out significant at day 30 $\left({ }^{*} p<0.001\right)$, respectively. Bars stand for standard deviation.

\subsubsection{Serology and Serum Bactericidal Activity (SBA) of Post-Vaccination Sera of Flock 2}

In an attempt to better understand the importance of antibody development to the extent of SBA, we performed a second experiment, using the same treatments as in the above but measuring antibody isotype titers by adding indirect ELISA (i-ELISA) to the antibody tests and increasing the number of vaccinated animals to eight.

As shown in Table 2, none of the sera samples had detectable antibody titers measured by MAT and CFT before vaccination. Serum sample number 4860421 was CFT and MAT negative 15 days post-vaccination but transformed positive at day 30 , also becoming positive for i-ELISA. Meanwhile, serum numbers 4860417, 4860422 and 4860423 transformed positive 30 days post-vaccination by i-ELISA. Serum sample number 4860419 showed a minimal MAT positivity at 30 days post-vaccination but remained negative by CFT and i-ELISA along the whole experiment. 
Table 2. Anti-Brucella-OPS serum titers depicted by three serological tests in the second vaccine experiment before and after ocular vaccination with B. melitensis Rev. 1 vaccine.

\begin{tabular}{cccccccccccc}
\hline & \multicolumn{1}{c}{ Serology Results } \\
\cline { 2 - 11 } Sheep Number & \multicolumn{3}{c}{ Day 0 (19 July 2021) } & \multicolumn{2}{c}{ Day 15 (3 August 2021) } & \multicolumn{2}{c}{ Day 30 (19 August 2021) } \\
\cline { 2 - 12 } & SAT & CFT & $\begin{array}{c}\text { ELISA IgG } \\
\text { (OD) }\end{array}$ & SAT & CFT & $\begin{array}{c}\text { ELISA } \\
\text { (OD) }\end{array}$ & $\begin{array}{c}\text { SAT } \\
\text { CFT }\end{array}$ & $\begin{array}{c}\text { ELISA IgG } \\
\text { (OD) }\end{array}$ \\
\hline 4860416 & Neg & Neg & 0.0805 & Neg & Neg & 0.077033333 & Neg & Neg & 0.078 \\
\hline 4860417 & Neg & Neg & 0.053 & $1: 20(+4)$ & Neg & 0.056 & $1: 20(+4)$ & Neg & 0.323 \\
\hline 4860418 & Neg & Neg & 0.062 & Neg & Neg & 0.054 & $1: 20(+4)$ & Neg & 0.071 \\
\hline 4860419 & Neg & Neg & 0.069 & Neg & Neg & 0.058 & $1: 40(+1)$ & Neg & 0.077 \\
\hline 4860420 & Neg & Neg & 0.082 & Neg & Neg & 0.056 & Neg & Neg & 0.0698 \\
\hline 4860421 & Neg & Neg & 0.088 & Neg & Neg & 0.053 & $1: 80(+1)$ & $1: 10+$ & 1.2682 \\
\hline 4860422 & Neg & Neg & 0.081 & Neg & Neg & 0.049 & $1: 20(+4)$ & Neg & 0.4757 \\
\hline 4860423 & Neg & Neg & 0.049 & Neg & Neg & 0.054 & Neg & Neg & 1.2935 \\
\hline
\end{tabular}

Neg stands for negative.

As shown in Table 2, CFT and MAT negative sera were still shown positive by i-ELISA, indicating the higher sensitivity of the i-ELISA method in comparison to the standard serology. In fact, CFT and SAT have been adjusted a priori to be able to perform as qualitative DIVA methods which excludes reading of vaccine elicited antibodies. Figures 2 and 3 show that serum samples before vaccination lacked anti-Brucella OPS antibodies but were endowed with a basic SBA level which varied among the serum samples between 8 to 13\% of cell killing between strain 16M (Figure 2) and Rev. 1 (Figure 3). SBA against both Rev. 1 and 16M strains rose up among serum samples number 4860417, 4860421, 4860422 and 4860423 which significantly correlated with development of IgG OPS anti-Brucella antibody titers in the same sera on day 30 post-vaccination (against 16M, $p<0.05,4860417 ; p<0.01$ 4860421, 4860422; $p<0.001,4860423$ and against Rev. 1 ( $p<0.05,4860417 ; p<0.01,4860421$; $p<0.001,4860422,4860423)$, Bonferroni's post hoc test. Supplementary Material Figure S3 summarizes the results of individual sera samples when combined into two groups, those which lacked i-ELISA titers and in correlation were not endowed with SBA in contrast to the other serum samples which possessed i-ELISA titers and were endowed with SBA, respectively. Bonferroni two-way ANOVA analysis showed the significant killing difference $(p>0.001)$ against B. melitensis $16 \mathrm{M}$ and B. melitensis Rev.1 with anti-Brucella OPS antibodies sera in comparison to sera-lacking anti-Brucella-OPS antibodies.

\subsubsection{Serology and Serum Bactericidal Activity (SBA) of Post-Infection Sera}

We also examined SBA in serum samples obtained from $B$. melitensis naturally infected sheep, selecting animals according to their positive CFT serology of $\geq 1: 20$ which indicated presence of IgG anti-Brucella antibodies in the serum. Because animals in the field are identified bona fide, without information on their serum activity before exposure to Brucella, we used baseline SBA values from the SBA data mentioned above among sheep before vaccination Figure 1. As can be seen in Figure 4, serum samples of infected animals demonstrated complement mediated cell killing against both strains, all showing a higher cell killing activity than their baseline response (horizontal broken line). In this test, killing was more effective against strain 16M than against vaccine strain Rev.1 (unpaired $t$-test, $p \leq 0.05)$ reiterating the observation discussed in Figure 1. 


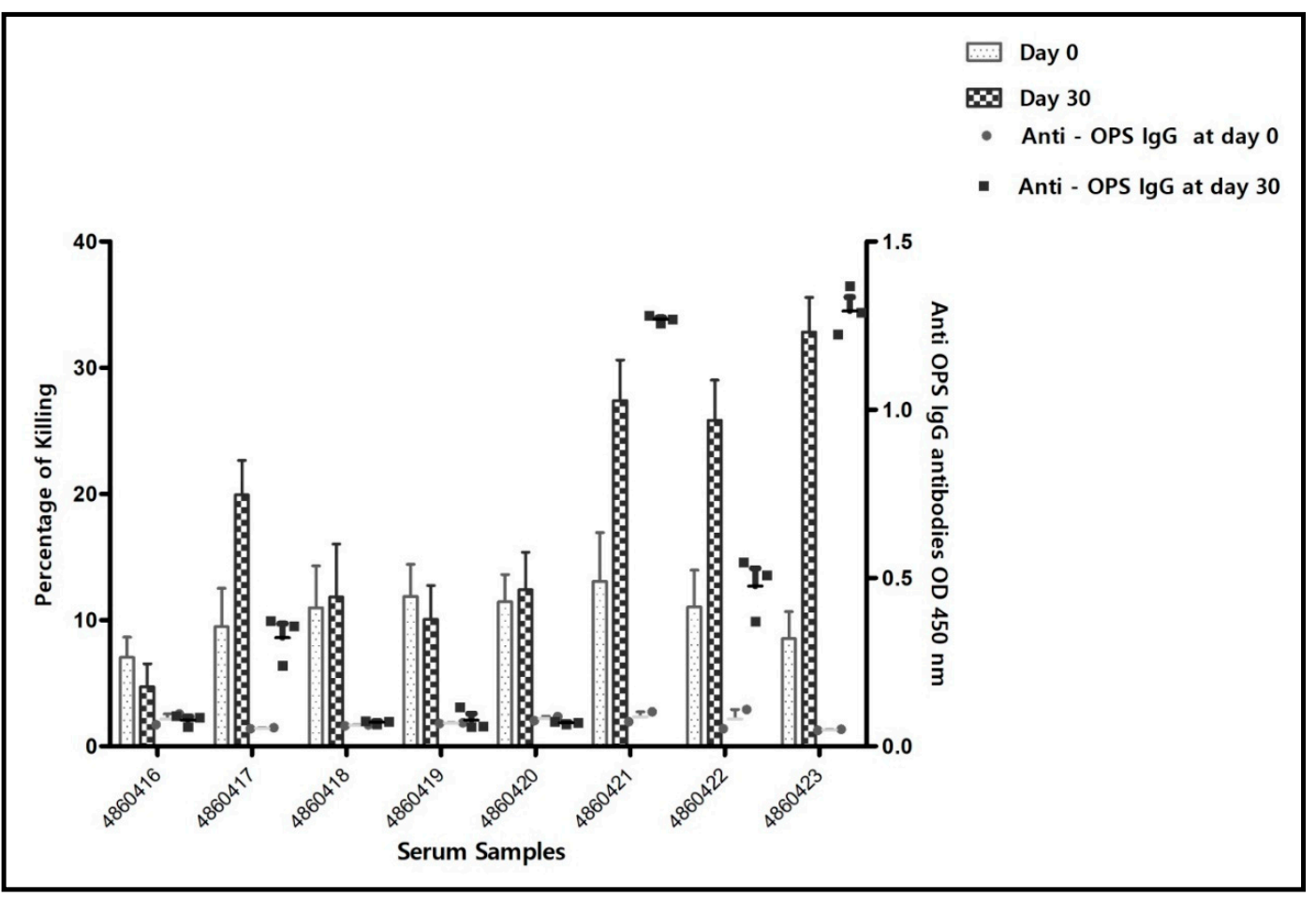

Figure 2. Percentage of cell killing of $B$. melitensis $16 \mathrm{M}$ cells by the individual serum samples on day 0 , prior to vaccination and day 30 post-vaccination period, along with development of anti-Brucella OPS i-ELISA titers respectively (results obtained in the second set of experiments). i-ELISA results are of one experiment in triplicates. SBA results represent data of percentage of cell killing from 4 experiments, each including duplicates. Bars stand for standard error of mean.

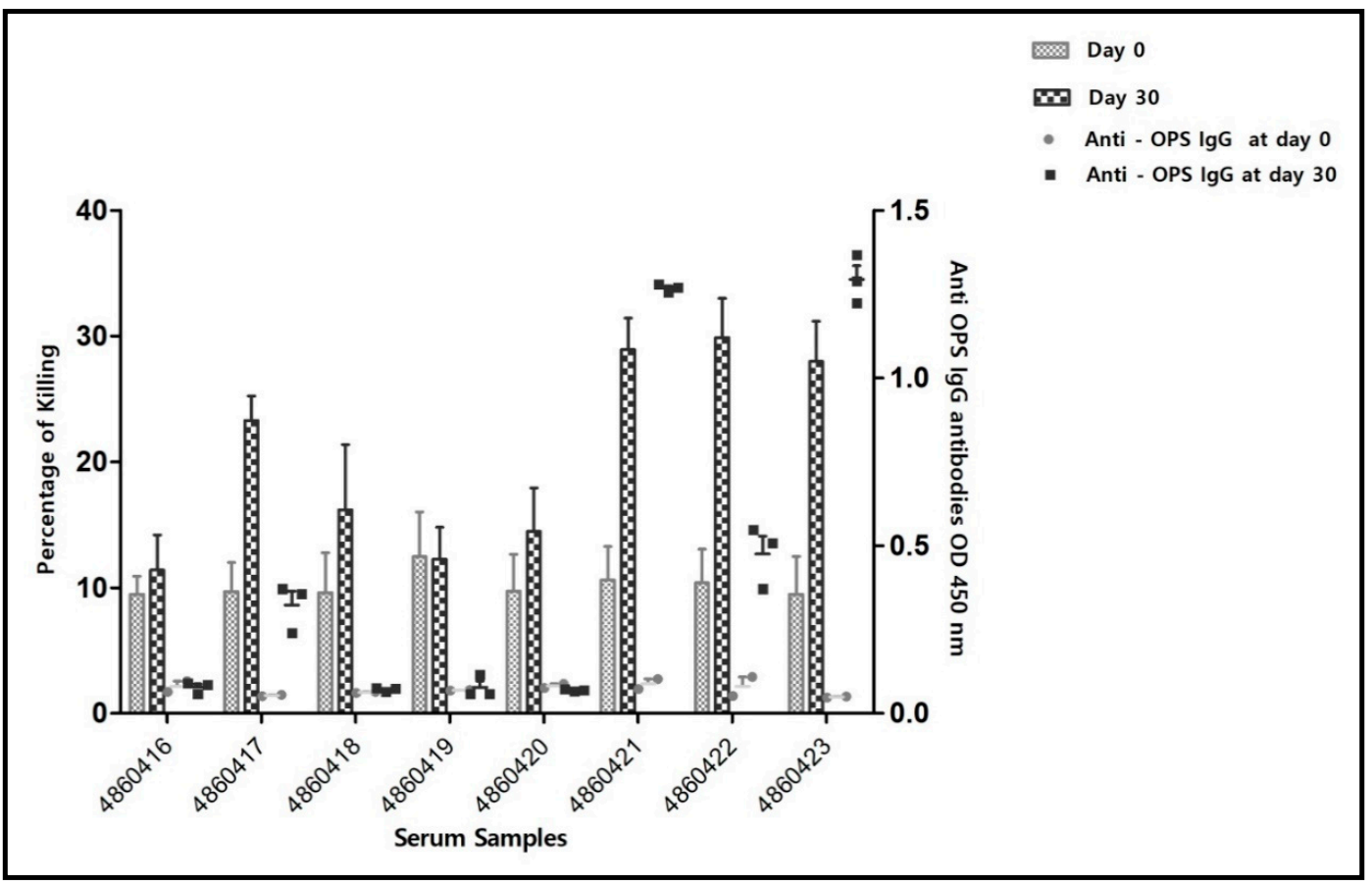

Figure 3. Percentage of cell killing of B. melitensis Rev.1 cells by the individual serum samples on day 0 , prior to vaccination and day 30 post-vaccination periods, along with the development of antiBrucella-OPS i-ELISA titers (results obtained in the second set of experiments). i-ELISA results are of one experiment in triplicates. SBA results represent data of percentage of killing from 4 experiments, each including duplicates. Bars stand for standard error of mean. 


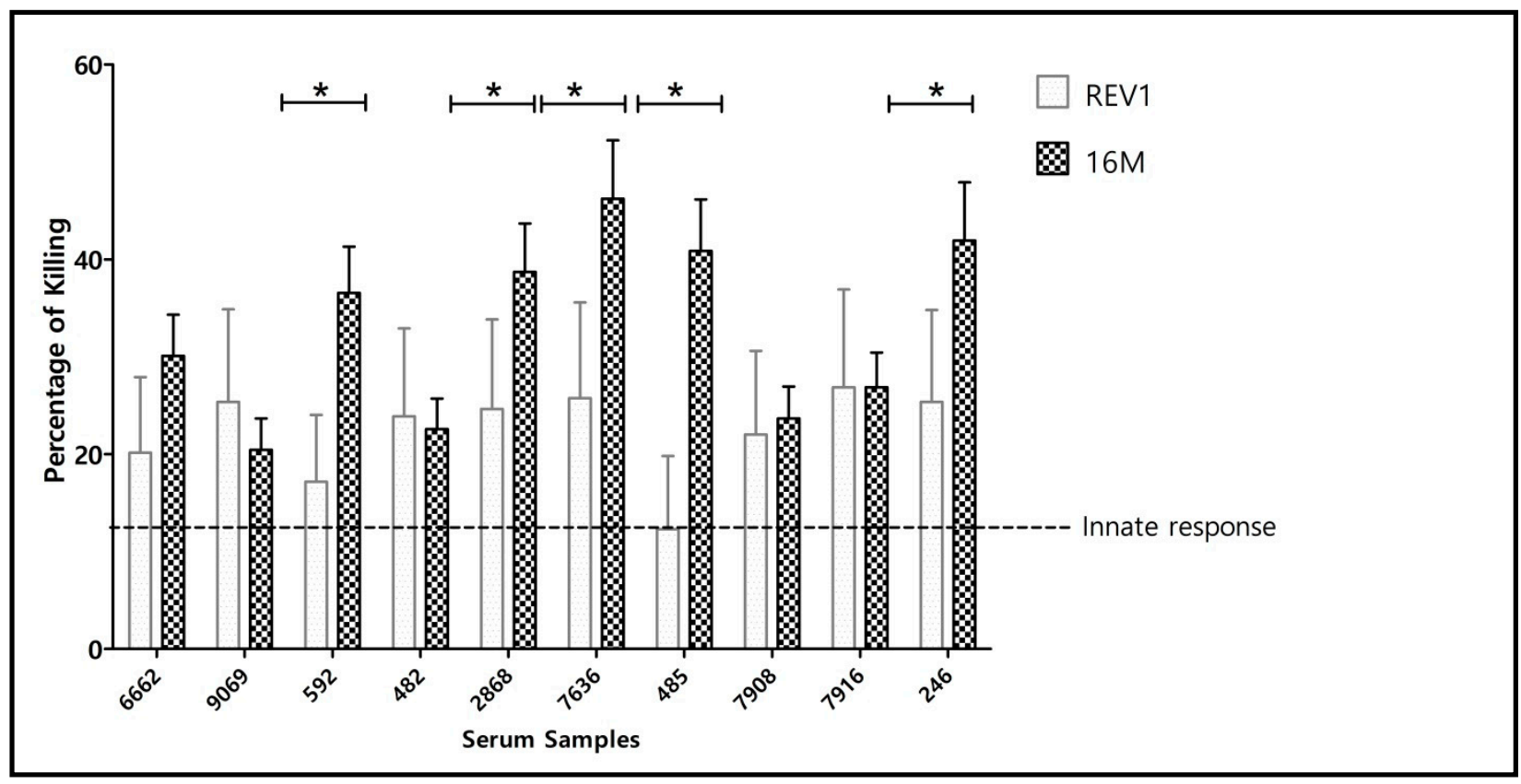

Figure 4. Percentage of cell killing of B. melitensis strain 16M and B. melitensis strain Rev. 1 Elberg by serum samples of infected sheep. Unpaired $T$-test shows overall significant difference between $16 \mathrm{M}$ and Rev. 1 cell killing $(p<0.05)$ (with Bonferroni correction for multiple comparisons), $\left({ }^{*} p<0.05\right)$ shows the significant difference in the killing activity of individual sera. Horizontal line depicts percentage of Brucella cell killing attributed to innate immunity (A generalized innate killing activity of sheep serum samples calculated as a mean value of killing results of the four serum samples prior to animal vaccination). Killing activity above this level is considered, therefore, to be contributed by any of anti-Brucella antibodies present in the reaction, including non-anti-OPS antibodies.

\section{Discussion}

Use of Rev. 1 vaccine has always been conceived effective in protection against brucellosis due to elicitation of the cellular arm of the immune response. In contrast, development of antibodies has been considered as interfering with DIVA diagnosis of vaccinated herds $[18,21,27,28]$. This led scientists to favor the ocular application of the vaccine throughout vaccination campaigns, and our manuscript addresses this point by showing that ocular vaccination still elicits antibodies which are not detectable by standard serological tests, whereas LPS ELISA can identify them. We have hypothesized that anti-Brucella-OPS antibodies elicited following Rev. 1 sheep vaccination, or otherwise sheep infection, would be functional in host protection. To test this hypothesis, two sets of experiments were designed on the basis of studying development of anti-OPS antibodies by both CFT and MAT serology in the first set and anti-Brucella-OPS indirect ELISA serology in the other set. We have furthered the experiment by testing first development of SBA in correlation with Rev. 1 ocular vaccination and secondly, in sera obtained after natural Brucella infection. The serum agglutination test (MAT), complement fixation test CFT and i-ELISA were used to indicate presence of IgM (MAT) and IgG antibodies (CFT and i-ELISA) in the serum samples) [24].

Because Rev. 1 is delivered in Israel by the ocular route, aiming at reducing antibody titers, we specifically selected sheep that best represent their antibody response to Rev. 1 vaccination through CFT, MAT analyses in the first set of experiment and including i-ELISA in the second test, assuming i-ELISA would reveal anti-Brucella-OPS antibodies which MAT and CFT are missing, respectively. We chose two $B$. melitensis strains as read out analytes, a typical strain of the genus (B. melitensis strain 16M), and its counter live attenuated vaccine strain Rev.1 Elberg, passage 101, 1970, best representing the authentic Rev. 1 clone first 
developed by Elberg in the 1950s [29], aiming also at revealing how its attenuation has affected cell susceptibility to SBA.

From the Rev. 1 pre- and post-vaccination sera testing, our data have reiterated a past notion that anti-Brucella serum antibodies participate in Brucella cell killing. In this study we have clearly shown the correlation between development of elevated antibody levels, mostly IgG, against Brucella-OPS in sheep and percentage of cell killing in both cases of Rev. 1 ocular vaccination or following natural infection, respectively. We have observed, however, that in the vaccine experiment, CFT-positive serum samples showed significantly lower SBA against Rev. 1 cells than against strain 16M (Figure 1, $p<0.001$; Bonferroni post hoc test) possibly explained by differences in the cell envelop between the vaccine strain and 16M, a typical strain of the genus [30]. One may thus take it one step further to hypothesize that vaccine strain Rev. 1 attenuation may have involved changes in its OPS structure.

Comparing between vaccine- and infection-induced antibodies provided a unique opportunity to test the functional responsiveness of the immune response against both Brucella strains. B. melitensis is naturally affiliated to small ruminants and B. abortus to cattle. Nevertheless, both strains share cross reactive antibodies against their OPS antigen making serology irrelevant in determining which was the etiological agent involved in an infection. Despite using the ocular vaccine, aimed at reducing the humoral response of the immune system, antibodies are developed by the host.

We demonstrate that anti-Brucella-OPS antibodies induced by vaccination or natural infection are functional and may contribute to preventing infection by activating a complement mediated cell-killing mechanism. Until now, development of anti-Brucella-OPS antibodies has been considered a flaw in the vaccination policy due to hampering DIVA serological surveillance studies following Rev. 1 vaccination campaigns. To overcome this problem, enforcing a stringent vaccination policy where only young replacement animals are vaccinated by a single-lifetime inoculation and flock coverage is confirmed would be necessary.

Similar to Rev. 1 vaccination, our results now show that natural infection also accounts for development of functional anti-Brucella OPS antibodies that participate in SBA against Brucella (Figure 4). However, in the case of infection it is understood that the field strain persists in the flock and animal culling is required to stop the spread of the disease to other animals.

Our results indicate an opportunity to improve vaccination effectiveness against brucellosis by increasing development of anti-Brucella-OPS bactericidal antibodies using a DIVA established vaccine, first proposed by Bundle and McGiven (18). It has been shown that conjugate vaccines against other bacterial pathogens such as Hemophilus influenzae type b, S. pneumoniae or Shigella can induce stronger binding and functional antibody responses as compared to the corresponding natural infections [31-33]. The development and use of a conjugate Brucella vaccine should, therefore, be sought as an ultimate solution to maintaining high coverage of herd immunity. Rev. 1 vaccination of replacement animals should nevertheless remain a major strategic tool in controlling the disease by strengthening individual immunity among the animals through prevention of abortions thus minimizing the risks of building up chronic brucellosis in the flock.

\section{Conclusions}

Rev. 1 vaccination as well as B. melitensis infection elicit functional anti-Brucella-OPS antibodies which kill Brucella cells in vitro by the classical complement mediated pathway. Rev. 1 vaccine, which is a live attenuated strain, survives in the host for a critical period required for the buildup of the adapted cellular arm of the immune response. However, this vaccine does have adverse effects; it causes abortions if used in pregnant ewes, it elicits persistent antibody titers which hamper DIVA diagnosis and it is zoonotic.

In view of our results, we assume that endowing the host with anti-Brucella-OPS antibodies could augment the innate immune response against brucellosis, therefore aiding 
in protection against invading Brucella organisms at earlier phase of infection. Whereas natural development of anti-Brucella-OPS antibodies is associated with a T-cell-independent pathway, using a conjugate vaccine which relies on construction of a smooth OPS antigen bound to a protein carrier would provide a solution to constructing a safe, acellular vaccine important to development of herd immunity.

Supplementary Materials: The following supporting information can be downloaded at: https: / / www.mdpi.com/article/10.3390/vaccines10020317/s1, Figure S1: Percentage of B. melitensis strain $16 \mathrm{M}$ cell killing by the individual serum samples; Figure S2: Percentages of B. melitensis Rev. 1 Elberg cell killing by the individual serum; Figure S3: Arithmetic mean value of Brucella cell killing efficiency by a combined pool of the 8 serum samples prior to vaccination and at day 30 in correlation with the presence of anti-Brucella OPS i-ELISA antibodies.

Author Contributions: Conceptualization, M.B. and D.C.; methodology, S.M.; software, S.M.; validation, D.C., M.B. and S.M.; formal analysis, S.M.; investigation, M.B.; resources, D.C.; data curation, S.M. and M.B.; writing—original draft preparation, S.M.; writing—review and editing, M.B. and D.C.; visualization, S.M.; supervision, M.B. and D.C.; project administration, D.C.; funding acquisition, D.C. All authors have read and agreed to the published version of the manuscript.

Funding: This project was partly supported by the Chief Scientist, Ministry of Agriculture, Israel Grant No. 13-18-0002.

Institutional Review Board Statement: Not applicable. Serum samples were provided by the field veterinary services as part of the Israeli brucellosis control program.

Institutional Consent Statement: Not applicable.

Acknowledgments: The authors would like to thank veterinary practitioners of the Israeli Veterinary Services who conducted field activities that are mentioned in this manuscript. Serological tests were performed by Svetlana Bardenstein and team at the National, OIE and FAO Reference laboratory, Israel. Shubham Mathur is a student at the Tel Aviv University School of Public Health, supported by the PI Foundation Charitable trust, Singhal Farm House, Near Air Force station Rajkori, New Delhi-110038 and the Manna Center Program for Food Safety \& Security at Tel Aviv University. This study is part of Shubham Mathur's PhD dissertation.

Conflicts of Interest: The authors declare no conflict of interest.

\section{References}

1. Xavier, M.N.; Paixao, T.A.; den Hartigh, A.B.; Tsolis, R.M.; Santos, R.L. Pathogenesis of Brucella spp. Open Vet. Sci. J. 2010, 4, 109-118. [CrossRef]

2. Seleem, M.N.; Boyle, S.M.; Sriranganathan, N. Brucellosis: A re-emerging zoonosis. Vet. Microbiol. 2010, 140, 392-398. [CrossRef] [PubMed]

3. Franco, M.P.; Mulder, M.; Gilman, R.H.; Smits, H.L. Human brucellosis. Lancet Infect. Dis. 2007, 7, 775-786. [CrossRef]

4. Moyle, P.M. Progress in vaccine development. Curr. Protoc. Microbiol. 2015, 36, 18.1.1-18.1.26. [CrossRef]

5. Wang, Z.; Wu, Q. Research progress in live attenuated Brucella vaccine development. Curr. Pharm. Biotechnol. 2013, 14, 887-896. [CrossRef]

6. Herzberg, M.; Elberg, S. Immunization against brucella infection. I. Isolation and characterization of a streptomycin-dependent mutant. J. Bacteriol. 1953, 66, 585-599. [CrossRef]

7. World Health Organization. The Development of New/Improved Brucellosis Vaccines: Report of WHO Meeting, Geneva, Switzerland, 11-12 December 1997; World Health Organization: Geneva, Switzerland, 1998; pp. 1-48.

8. Ghanem-Zoubi, N.; Eljay, S.P.; Anis, E.; Paul, M. Reemergence of Human Brucellosis in Israel. Isr. Med. Assoc. J. $2019,21,10-12$.

9. Banai, M. Control of small ruminant brucellosis by use of Brucella melitensis Rev.1 vaccine: Laboratory aspects and field observations. Vet. Microbiol. 2002, 90, 497-519. [CrossRef]

10. Ko, J.; Splitter, G.A. Molecular host-pathogen interaction in brucellosis: Current understanding and future approaches to vaccine development for mice and humans. Clin. Microbiol. Rev. 2003, 16, 65-78. [CrossRef]

11. Corbeil, L.B.; Blau, K.; Inzana, T.J.; Nielsen, K.H.; Jacobson, R.H.; Corbeil, R.R.; Winter, A.J. Killing of brucella abortus by bovine serum. Infect. Immun. 1988, 56, 3251-3261. [CrossRef]

12. Paixão, T.A.; Costa, E.A.; Xavier, M.N.; Silva, T.M.A.; Santos, R.L. Natural resistance and innate immunity in brucellosis. Vet. Immunol. Immunopathol. 2009, 1, 21-37.

13. Skendros, P.; Boura, P. Immunity to brucellosis. OIE Rev. Sci. Tech. 2013, 32, 137-147. [CrossRef] [PubMed] 
14. Forget, A.; Riendeau, C. Enhancement activity of anti-brucella sera in experimental Brucella abortus infection in mice. Rev. Can. Biol. 1977, 36, 239-243. [PubMed]

15. Limet, J.; Plommet, A.M.; Dubray, G.; Plommet, M. Immunity conferred upon mice by anti-LPS monoclonal antibodies in murine Brucellosis. Ann. l'Institut Pasteur Immunol. 1987, 138, 417-424. [CrossRef]

16. Phillips, M.; Deyoe, B.L.; Canning, P.C. Protection of mice against Brucella abortus infection by inoculation with monoclonal antibodies recognizing Brucella O-antigen. Am. J. Vet. Res. 1989, 50, 2158-2161.

17. Adone, R.; Francia, M.; Pistoia, C.; Petrucci, P.; Pesciaroli, M.; Pasquali, P. Protective role of antibodies induced by Brucella melitensis B115 against B. melitensis and Brucella abortus infections in mice. Vaccine 2012, 30, 3992-3995. [CrossRef]

18. Bundle, D.R.; McGiven, J. Brucellosis: Improved Diagnostics and Vaccine Insights from Synthetic Glycans. Acc. Chem. Res. 2017, 50, 2958-2967. [CrossRef]

19. Jang, M.S.; Sahastrabuddhe, S.; Yun, C.H.; Han, S.H.; Yang, J.S. Serum bactericidal assay for the evaluation of typhoid vaccine using a semi-automated colony-counting method. Microb. Pathog. 2016, 97, 19-26. [CrossRef]

20. Barquero-Calvo, E.; Chaves-Olarte, E.; Weiss, D.S.; Guzmán-Verri, C.; Chacón-Díaz, C.; Rucavado, A.; Moriyón, I.; Moreno, E. Brucella abortus uses a stealthy strategy to avoid activation of the innate immune system during the onset of infection. PLOS ONE 2007, 2, e631. [CrossRef]

21. Mandal, S.S.; Duncombe, L.; Ganesh, N.V.; Sarkar, S.; Howells, L.; Hogarth, P.J.; Bundle, D.R.; McGiven, J. Novel Solutions for Vaccines and Diagnostics to Combat Brucellosis. ACS Cent. Sci. 2017, 3, 224-231. [CrossRef]

22. McGiven, J.; Howells, L.; Duncombe, L.; Stack, J.; Ganesh, N.V.; Guiard, J.; Bundle, D.R. Improved serodiagnosis of bovine brucellosis by novel synthetic oligosaccharide antigens representing the capping M epitope elements of Brucella O-Polysaccharide. J. Clin. Microbiol. 2015, 53, 1204-1210. [CrossRef] [PubMed]

23. Alton, G.G.; Jones, L.M.; Pietz, D.E.; World Health Organization; Food and Agriculture Organization of the United Nations. Laboratory Techniques in Brucellosis, 2nd ed.; World Health Organization: Geneva, Switzerland, 1975.

24. Baum, M.; Zamir, O.; Bergman-Rios, R.; Katz, E.; Beider, Z.; Cohen, A.; Banai, M. Comparative evaluation of microagglutination test and serum agglutination test as supplementary diagnostic methods for brucellosis. J. Clin. Microbiol. 1995, 33, $2166-2170$. [CrossRef] [PubMed]

25. Oswald, I.P.; Lantier, F.; Bourgy, G. Classical and alternative pathway haemolytic activities of ovine complement: Variations with age and sex. Vet. Immunol. Immunopathol. 1990, 24, 259-266. [CrossRef]

26. Estein, S.M.; Cheves, P.C.; Fiorentino, M.A.; Cassataro, J.; Paolicchi, F.A.; Bowden, R.A. Immunogenicity of recombinant Omp31 from Brucella melitensis in rams and serum bactericidal activity against B. ovis. Vet. Microbiol. 2004, 102, 203-213. [CrossRef]

27. Díaz, A.G.; Clausse, M.; Paolicchi, F.A.; Fiorentino, M.A.; Ghersi, G.; Zylberman, V.; Goldbaum, F.A.; Estein, S.M. Immune response and serum bactericidal activity against Brucella ovis elicited using a short immunization schedule with the polymeric antigen BLSOmp31 in rams. Vet. Immunol. Immunopathol. 2013, 154, 36-41. [CrossRef]

28. Banai, M.; Itin, R.; Bardenstein, S. Perspectives and outcomes of the activity of a reference laboratory for brucellosis. Front. Vet. Sci. 2018, 4, 234. [CrossRef]

29. Corbel, M.M.J. Brucellosis in Humans and Animals; WHO Library Cataloguing-in-Publication Data; WHO/CDS/EPR/2006.7; WHO: Geneva, Switzerland, 2006; pp. 1-88.

30. González, D.; Grilló, M.J.; De Miguel, M.J.; Ali, T.; Arce-Gorvel, V.; Delrue, R.M.; Conde-Álvarez, R.; Muñoz, P.; López-Goñi, I.; Iriarte, M.; et al. Brucellosis vaccines: Assessment of Brucella melitensis lipopolysaccharide rough mutants defective in core and O-polysaccharide synthesis and export. PLOS ONE 2008, 3, e2760. [CrossRef]

31. Robbins, J.B.; Chu, C.; Schneerson, R. Hypothesis for vaccine development: Protective immunity to enteric diseases caused by nontyphoidal salmonellae and shigellae may be conferred by serum IgG antibodies to the O-specific polysaccharide of their lipopolysaccharides. Clin. Infect. Dis. 1992, 15, 346-361. [CrossRef]

32. Taylor, D.N.; Trofa, A.C.; Sadoff, J.; Chu, C.; Bryla, D.; Shiloach, J.; Cohen, D.; Ashkenazi, S.; Lerman, Y.; Egan, W. Synthesis, characterization, and clinical evaluation of conjugate vaccines composed of the O-specific polysaccharides of Shigella dysenteriae type 1, Shigella flexneri type 2a, and Shigella sonnei bound to bacterial toxoids. Infect. Immun. 1993, 61, 3678-3687. [CrossRef]

33. Pollard, A.J.; Bijker, E.M. A guide to vaccinology: From basic principles to new developments. Nat. Rev. Immunol. 2021, 21, 83-100. [CrossRef] 